\title{
SENSITIVITY OF THE MEIOTIC STAGE TO HYPERTHERMIA DURING IN VITRO MATURATION OF PORCINE OOCYTES
}

\author{
Katsutoshi NiSHIO ${ }^{1}$, Mado YAMAZAKI ${ }^{2}$, Masayasu TANIGUCHI ${ }^{2}$, Kazuhiko BESSHI ${ }^{3}$, \\ Fumio Morita $^{3}$, Toshiki KUnIHARA ${ }^{1}$, Fuminori TANIHARA ${ }^{1}$, Tatsuya TAKEMOTO $^{4}$ \\ and Takeshige Oтог ${ }^{*}$ \\ ${ }^{1}$ Laboratory of Animal Reproduction, Faculty of Bioscience and Bioindustry (Ishii campus), \\ Tokushima University, Ishii, Myozai-gun, Tokushima 779-3233, Japan; ${ }^{2}$ Joint Faculty of \\ Veterinary Science, Yamaguchi University, Yamaguchi, Japan; ${ }^{3}$ Drug Safety Research \\ Laboratory, Taiho Pharmaceutical Co. Ltd., Tokushima, Japan; ${ }^{4}$ Fujii Memorial Institute of \\ Medical Sciences, Tokushima University, Tokushima, Japan
}

(Received 3 August 2016; accepted 2 November 2016)

\begin{abstract}
The present study was conducted to clarify whether the meiotic stage of porcine oocytes has the highest sensitivity to hyperthermia during in vitro maturation by evaluating meiotic competence and DNA damage. Oocytes were exposed to $41{ }^{\circ} \mathrm{C}$ for $12 \mathrm{~h}$ at various intervals during $48 \mathrm{~h}$ of maturation culture. When the oocytes were exposed to $41{ }^{\circ} \mathrm{C}$ from 12 to $24 \mathrm{~h}$ of the maturation culture, the proportion of oocytes reaching metaphase II (MII) decreased as compared to the control oocytes cultured at $38.5^{\circ} \mathrm{C}(\mathrm{P}<0.05)$. Moreover, the proportions of DNA fragmentation in all oocytes exposed to $41^{\circ} \mathrm{C}$ in each culture period after $12 \mathrm{~h}$ from the start of maturation culture were significantly higher $(\mathrm{P}<0.05)$ than for the control oocytes. When the meiotic stage of oocytes cultured at $38.5^{\circ} \mathrm{C}$ between 12 and $24 \mathrm{~h}$ was examined, the majority of oocytes remained at the germinal vesicle (GV) stage at $12 \mathrm{~h}$ and approximately half of the oocytes reached metaphase I (MI) at $24 \mathrm{~h}$. These results indicate that the meiotic stage of porcine oocytes having the highest sensitivity to hyperthermia during in vitro maturation is a transition period from the GV stage to the MI stage.
\end{abstract}

Key words: Heat stress, maturation, meiotic stage, quality, sensitivity

Heat stress (HS) can compromise reproductive events by decreasing the expression of oestrous behaviour, altering follicular development, compromising oocyte competence, and inhibiting embryonic development (Wolfenson et al., 2000; Hansen et al., 2001). HS disrupts the synthesis of the steroid hormone involved in the regulating mechanism of oocyte maturation. Moreover, HS during maturation has been suggested to alter both nuclear and cytoskeletal configurations in oocytes, reduce developmental competence, and increase oocyte apoptosis (Ju and Tseng, 2004; Roth and Hansen, 2004). In a previous study, we

\footnotetext{
"Corresponding author; E-mail: otoi@tokushima-u.ac.jp; Phone/Fax: 0081 (88) 635-0963
} 
demonstrated that the exposure of porcine oocytes at the germinal vesicle $(\mathrm{GV})$ stage to an elevated temperature $\left(41^{\circ} \mathrm{C}\right)$ causes a reduction in their maturation rate and increases the proportion of oocytes with DNA-fragmented nuclei. Hypothermia-mediated DNA damage to the cumulus cells surrounding the oocyte during maturation reduces the quality of porcine oocytes, resulting in a failure of meiotic maturation (Yuan et al., 2008). The deleterious effects of hyperthermia on porcine oocytes are potentially irreversible, even if the oocytes are returned to normal culture conditions (Ju and Tseng, 2004). However, the meiotic stage of oocytes, which has the highest sensitivity to hyperthermia during maturation, remains unclear.

The objective of this study was to clarify the meiotic stage of porcine oocytes that has the highest sensitivity to hyperthermia by assessing the meiotic maturation and DNA damage of oocytes exposed to an elevated temperature $\left(41^{\circ} \mathrm{C}\right)$ for $12 \mathrm{~h}$ at various intervals during maturation culture.

\section{Materials and methods}

\section{Exposure to an elevated temperature and in vitro maturation (IVM) of oocytes}

Porcine ovaries were obtained from prepubertal crossbred gilts (Landrace, Large White and Duroc breeds) at a slaughterhouse in April to June 2014 and transported to the laboratory within $3 \mathrm{~h}$ in physiological saline $(0.9 \%(\mathrm{w} / \mathrm{v})$ $\mathrm{NaCl}$ ) at $30^{\circ} \mathrm{C}$. The ovaries were washed three times with modified phosphatebuffered saline (m-PBS; Nihonzenyaku, Fukushima, Japan) supplemented with $100 \mathrm{IU} / \mathrm{ml}$ penicillin $\mathrm{G}$ potassium (Meiji, Tokyo, Japan) and $0.1 \mathrm{mg} / \mathrm{ml}$ streptomycin sulphate (Meiji). Cumulus-oocyte complexes (COCs) were collected from 3- to 6-mm follicles using a surgical blade. Only COCs with a uniform, darkpigmented ooplasm and an intact cumulus cell mass were collected. Approximately $50 \mathrm{COCs}$ were then cultured in $500 \mu \mathrm{l}$ of maturation medium consisting of 25 mM HEPES tissue culture medium 199 with Earle's salts (TCM 199; Invitrogen Co., Carlsbad, CA, USA) that was supplemented with $10 \%(\mathrm{v} / \mathrm{v})$ porcine follicular fluid, $0.6 \mathrm{mM}$ cysteine (Sigma-Aldrich, St. Louis, MO, USA), $50 \mu \mathrm{M}$ sodium pyruvate (Sigma-Aldrich), $2 \mathrm{mg} / \mathrm{ml}$ D-sorbitol (Wako Pure Chemical Industries Ltd., Osaka, Japan), $1 \mu \mathrm{g} / \mathrm{ml} 17 \beta$-oestradiol (Sigma-Aldrich), $10 \mathrm{IU} / \mathrm{ml}$ equine chorionic gonadotropin (Kyoritu Seiyaku, Tokyo, Japan), $10 \mathrm{IU} / \mathrm{ml}$ human chorionic gonadotropin (Kyoritu Seiyaku), and $50 \mu \mathrm{g} / \mathrm{ml}$ gentamicin (SigmaAldrich) for $24 \mathrm{~h}$ in 4-well dishes (Nunc A/S, Roskilde, Denmark). Subsequently, the COCs were transferred into maturation medium without hormone supplementation and cultured for an additional $24 \mathrm{~h}$ according to the method previously described by Namula et al. (2013). 


\section{Analysis of the meiotic stage and DNA damage of oocytes}

After maturation culture, the meiotic stage and DNA damage of oocytes were analysed by a combined technique for simultaneous nuclear staining and terminal deoxynucleotidyl transferase (TdT) nick-end labelling (TUNEL) using a modification of the procedures previously described by Otoi et al. (1999). Briefly, oocytes were mechanically denuded from cumulus cells in Dulbecco's PBS (DPBS; Invitrogen Co.) that was supplemented with $1 \mathrm{mg} / \mathrm{mL}$ hyaluronidase (Sigma). Denuded oocytes were fixed overnight at $4{ }^{\circ} \mathrm{C}$ in $3.7 \%(\mathrm{w} / \mathrm{v})$ paraformaldehyde diluted in DPBS. After fixation, the oocytes were permeabilised in DPBS containing $0.1 \%(\mathrm{v} / \mathrm{v})$ Triton-X100 for $40 \mathrm{~min}$. They were subsequently incubated overnight at $4{ }^{\circ} \mathrm{C}$ in DPBS containing $10 \mathrm{mg} / \mathrm{ml}$ bovine serum albumin (A9647, Sigma-Aldrich). The oocytes were then incubated in fluoresceinconjugated 2'-deoxyuridine-5'-triphosphate and terminal deoxynucleotidyl transferase (TUNEL reagent; Roche Diagnostics, Tokyo, Japan) for $1 \mathrm{~h}$ at $38.5^{\circ} \mathrm{C}$. After TUNEL staining, the oocytes were counterstained with $1 \mu \mathrm{g} / \mathrm{ml}$ DAPI (Invitrogen Co.) for $10 \mathrm{~min}$, then they were treated with an anti-bleaching solution (Slow-Fade; Molecular Probes Inc., Eugene, OR, USA), mounted on a glass slide, and sealed with clear nail polish. Labelled oocytes were examined using a microscope (Eclipse 80i, Nikon, Tokyo, Japan) with epifluorescence illumination. They were classified according to chromatin configuration as being in the germinal vesicle $(\mathrm{GV})$, condensed chromatin (CC), metaphase I (MI), anaphase I to telophase I (AT), or metaphase II (MII) stage. Those with diffusely stained cytoplasm characteristics of nonviable cells and those in which chromatin was unidentifiable or not visible were excluded from DNA damage analysis.

To assess the meiotic stage of oocytes cultured at $38.5^{\circ} \mathrm{C}$ for each period, oocytes were fixed and permeabilised in DPBS containing $3.7 \%(\mathrm{w} / \mathrm{v})$ paraformaldehyde and 1\% (v/v) Triton X-100 (Sigma-Aldrich) at room temperature for $15 \mathrm{~min}$. They were then incubated in DPBS containing $0.3 \%(\mathrm{w} / \mathrm{v})$ polyvinylpyrrolidone at room temperature for another $15 \mathrm{~min}$. The oocytes were placed in a drop of mounting medium consisting of $90 \%(\mathrm{v} / \mathrm{v})$ glycerol with $1.9 \mu \mathrm{M}$ Hoechst 33342 (Sigma-Aldrich) on a slide, covered with a coverslip supported by four droplets of Vaseline/paraffin, incubated overnight at $4{ }^{\circ} \mathrm{C}$ and examined under a fluorescence microscope. The meiotic stage of oocytes was classified as described above.

Experiment 1. To assess the sensitivity of the meiotic stage of porcine oocytes to hyperthermia, the COCs were randomly assigned to five treatment groups and then cultured in maturation medium at $41{ }^{\circ} \mathrm{C}$ for $12 \mathrm{~h}$ in each period during maturation culture. The $\mathrm{COC}$ incubations were performed in a $38.5^{\circ} \mathrm{C}$ humidified incubator containing $5 \% \mathrm{CO}_{2}$ with an exposure period of $41{ }^{\circ} \mathrm{C}$. After $48 \mathrm{~h}$ of IVM culture, the oocytes were fixed and stained to examine the nuclear status and DNA damage of oocytes exposed to $41{ }^{\circ} \mathrm{C}$. 
Experiment 2. In Experiment 1, the sensitivity of porcine oocytes exposed to hyperthermia from $12 \mathrm{~h}$ to $24 \mathrm{~h}$ after the start of maturation culture was higher than that of the other exposed groups. Therefore, the meiotic stages of oocytes cultured in a $38.5{ }^{\circ} \mathrm{C}$ humidified incubator containing $5 \% \mathrm{CO}_{2}$ for each period during $48 \mathrm{~h}$ of maturation culture and between 12 and $24 \mathrm{~h}$ were examined.

\section{Statistical analysis}

The data are expressed as means \pm SEM. The proportions of oocytes reaching each stage and oocytes with DNA-fragmented nuclei were subjected to arcsine transformation before performing an analysis of variance (ANOVA). The transformed data were tested by ANOVA, which was followed by the post hoc Fisher's protected least significant difference test (PLSD test) using the Statview program (Abacus Concepts, Inc., Berkeley, CA, USA). Differences at a probability value $(\mathrm{P})$ of 0.05 or less were considered significant.

\section{Results}

\section{Experiment 1}

As shown in Table 1 , when the oocytes were exposed to $41^{\circ} \mathrm{C}$ from 12 to $24 \mathrm{~h}$, the proportions of oocytes that remained at MI increased and those of oocytes reaching MII decreased compared with control oocytes cultured at $38.5^{\circ} \mathrm{C}$ $(\mathrm{P}<0.05)$. Moreover, the proportions of DNA fragmentation in the total oocytes exposed to $41{ }^{\circ} \mathrm{C}$ at each culture period after $12 \mathrm{~h}$ from the start of maturation culture were significantly higher $(\mathrm{P}<0.05)$ than those of the control oocytes (Fig. 1). The proportions of MII-stage oocytes with DNA-fragmented nuclei tended to be higher in oocytes exposed to $41^{\circ} \mathrm{C}$ after $12 \mathrm{~h}$ of maturation culture than in the control oocytes $(\mathrm{P}<0.1)$.

\section{Experiment 2}

As shown in Fig. 2A, when the meiotic stages of the oocytes were examined at various intervals during maturation culture, the proportions of oocytes remaining at the GV stage dramatically decreased from $74.8 \%$ to $22.5 \%$ between 12 and $24 \mathrm{~h}$ after the start of maturation culture. The proportions of oocytes at the $\mathrm{CC}$ and MI stages increased at $24 \mathrm{~h}$ of maturation culture. The proportion $(47.5 \%)$ of CC-stage oocytes reached a maximum at $20 \mathrm{~h}$, and approximately half (44.9\%) of the oocytes reached MI at $24 \mathrm{~h}$ (Fig. 2B). 


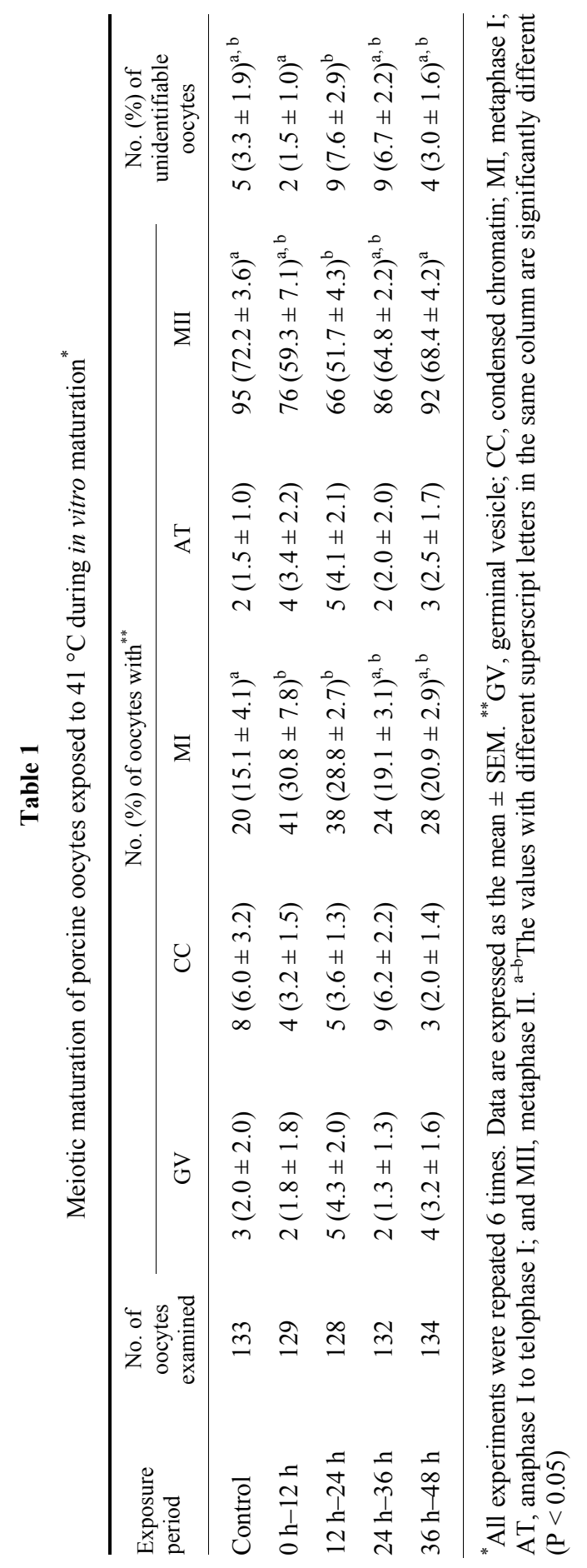


A

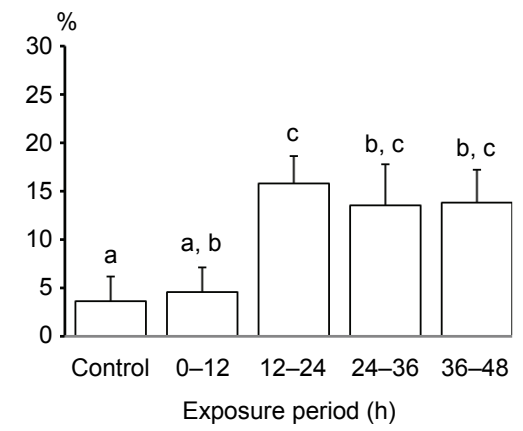

B

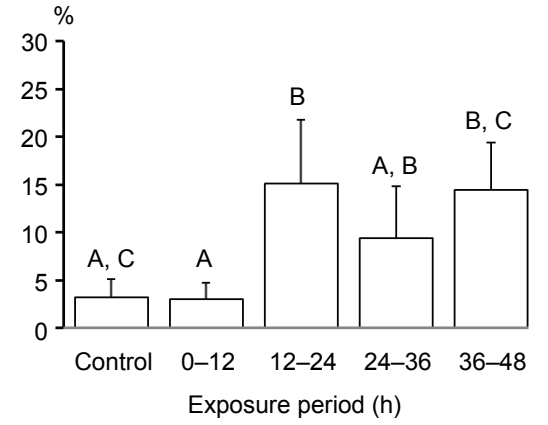

Fig. 1. Effects of porcine oocyte exposure to $41^{\circ} \mathrm{C}$ for $12 \mathrm{~h}$ during maturation culture on the proportions of total (A) and metaphase II (B) oocytes with DNA-fragmented nuclei. Control oocytes were cultured for $48 \mathrm{~h}$ without exposure to $41^{\circ} \mathrm{C}$. Proportions were calculated by dividing the number of oocytes with DNA-fragmented nuclei by the total number of oocytes examined and metaphase II oocytes. Each bar represents the mean \pm SEM. Bars with different letters differ significantly $(\mathrm{a}-\mathrm{c} ; \mathrm{P}<0.05, \mathrm{~A}-\mathrm{C} ; \mathrm{P}<0.1)$

A

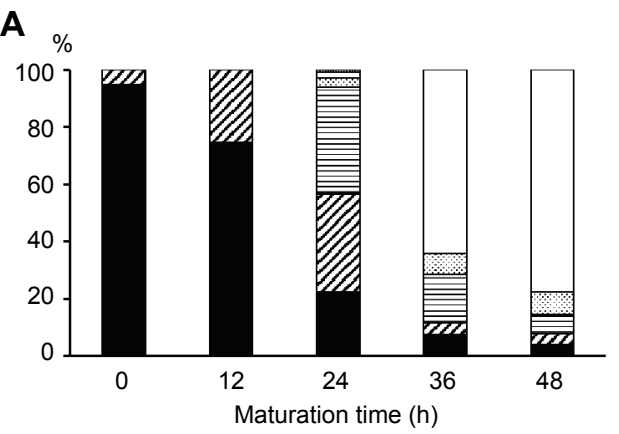

B

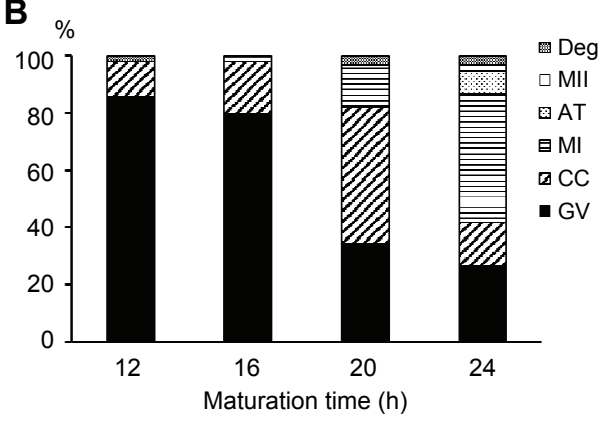

Fig. 2. Meiotic stage of porcine oocytes cultured for each time period during $48 \mathrm{~h}(\mathrm{~A})$ and between 12 and $24 \mathrm{~h}$ (B) of maturation culture. All oocytes cultured at $38.5^{\circ} \mathrm{C}$ for each time period during $48 \mathrm{~h}$ (116-120 oocytes) and between 12 and $24 \mathrm{~h}$ (98-99 oocytes) were used for estimating the meiotic stage

\section{Discussion}

Our previous study demonstrated that when porcine oocytes were exposed to $41.0^{\circ} \mathrm{C}$ for the entire period of maturation culture, their meiotic competence decreased, but the oocytes could mature and develop to the blastocyst stage after fertilisation (Do et al., 2015). In the present study, porcine oocytes were exposed to $41.0^{\circ} \mathrm{C}$ for $12 \mathrm{~h}$ at each period of maturation culture to clarify the meiotic stage of porcine oocytes that had the highest sensitivity to hyperthermia. We confirmed that the exposure of porcine oocytes to $41{ }^{\circ} \mathrm{C}$ for $12 \mathrm{~h}$ decreased the meiotic competence of oocytes and increased the DNA damage of all and MII-stage oocytes. Moreover, porcine oocytes cultured from 12 to $24 \mathrm{~h}$ after the start of maturation culture had a higher sensitivity to elevated temperature. 
The cooling of mammalian oocytes to sub-physiological temperatures is well known to affect their viability through inducing various abnormalities at all stages of meiosis (Moor and Crosby, 1985; Heyman et al., 1986; Pickering et al., 1990; Aman and Parks, 1994). In particular, porcine oocytes at the GV stage have been demonstrated to have a high sensitivity to chilling (Didion et al., 1990). Similarly, heat stress during porcine oocyte maturation has been shown to retard the nuclear maturation of oocytes, resulting in poor oocyte quality and low potency of oocyte development (Tseng et al., 2006; Yuan et al., 2008). Our previous study demonstrated that exposure of porcine oocytes at the GV stage to $41^{\circ} \mathrm{C}$ for $1 \mathrm{~h}$ reduced their maturation rate and increased the proportion of oocytes with DNA-fragmented nuclei (Barati et al., 2008). Yuan et al. (2008) also reported that the maturation rates of oocytes at the germinal vesicle breakdown (GVBD) stage decreased with exposure to $42{ }^{\circ} \mathrm{C}$ for $1 \mathrm{~h}$. It has been suggested that abnormalities in the chromosomes, spindle microtubules and pericytoplasmic microtubules of porcine oocytes occurred when the oocytes were exposed to an elevated temperature for even a short time (Ju and Tseng, 2004). Moreover, heat shock during oocyte maturation has been shown to promote an apoptotic response that is mediated by group II caspases, which are responsible for the destruction of structural and regulatory proteins that leads to DNA damage and cell demise (Chang and Yang, 2000; Roth and Hansen, 2004). Activation of the apoptotic processes mediated by group II caspases is a critical mechanism that is responsible for disrupting the oocyte capacity to cleave and develop further (Roth and Hansen, 2004). Although the detrimental effects of heat shock on the meiotic competence and quality of oocytes have been demonstrated, the meiotic stage of oocytes with high sensitivity to hyperthermia has remained unclear. In the current study, we clearly showed that the detrimental effects of hyperthermia become more apparent for the maturation rates and DNA damage of oocytes that were exposed to $41.0^{\circ} \mathrm{C}$ between 12 and $24 \mathrm{~h}$ after the start of maturation culture. At that time, oocytes resumed meiosis from the GV stage, and the majority of oocytes reached the CC- or MI-stage after $24 \mathrm{~h}$ in culture. In the detailed analysis of the meiotic stage of oocytes between 12 and $24 \mathrm{~h}$ in culture, GVBD started in the majority of oocytes after $20 \mathrm{~h}$ in culture. These results are similar to those obtained in the experiment by Nobata et al. (2013), who reported that porcine oocytes remained at the GV stage after $12 \mathrm{~h}$ of maturation culture and GVBD started after $18 \mathrm{~h}$. Moreover, we observed that the proportion of oocytes at the GVBD stage reached the maximum at $20 \mathrm{~h}$, and approximately half of the oocytes reached the MI stage at $24 \mathrm{~h}$. Therefore, our results indicate that the transition period from the GV stage to the MI stage has a higher sensitivity to elevated temperature.

In summary, the results of the present study demonstrate that porcine oocytes cultured from 12 to $24 \mathrm{~h}$ after the start of maturation culture have a higher sensitivity to hyperthermia, and their meiotic stages were from the GV to the MI stage. 


\section{Acknowledgements}

We thank the Meat Inspection Office of Kitakyushu city (Japan) for supplying the porcine ovaries. This work was supported in part by the Japan Science and Technology Agency/Japan International Co-operation Agency, Science and Technology Research Partnership for Sustainable Development (JST/JICA, SATREPS).

\section{References}

Aman, R. R. and Parks, J. E. (1994): Effects of cooling and rewarming on the meiotic spindle and chromosomes of in vitro-matured bovine oocytes. Biol. Reprod. 50, 103-110.

Barati, F., Agung, B., Wongsrikeao, P., Taniguchi, M., Nagai, T. and Otoi, T. (2008): Meiotic competence and DNA damage of porcine oocytes exposed to an elevated temperature. Theriogenology 69, 767-772.

Chang, H. Y. and Yang, X. (2000): Proteases for cell suicide: functions and regulation of caspases. Microbiol. Mol. Biol. Rev. 64, 821-846.

Didion, B. A., Pomp, D., Martin, M. J., Homanics, G. E. and Markert, C. L. (1990): Observations on the cooling and cryopreservation of pig oocytes at the germinal vesicle stage. J. Anim. Sci. 68, 2803-2810.

Do, L. T., Luu, V. V., Morita, Y., Taniguchi, M., Nii, M., Peter, A. T. and Otoi, T. (2015): Astaxanthin present in the maturation medium reduces negative effects of heat shock on the developmental competence of porcine oocytes. Reprod. Biol. 15, 86-93.

Hansen, P. J., Drost, M., Rivera, R. M., Paula-Lopes, F. F., al-Katanani, Y. M., Krininger, C. E., 3rd and Chase, C. C., Jr. (2001): Adverse impact of heat stress on embryo production: causes and strategies for mitigation. Theriogenology 55, 91-103.

Heyman, Y., Smorag, Z., Katska, L. and Vincent, C. (1986): Influence of carbohydrates, cooling and rapid freezing on viability of bovine non-matured oocytes or 1-cell fertilized eggs. Cryo-Letters 7, 170-183.

Ju, J. C. and Tseng, J. K. (2004): Nuclear and cytoskeletal alterations of in vitro matured porcine oocytes under hyperthermia. Mol. Reprod. Dev. 68, 125-133.

Moor, R. and Crosby, I. (1985): Temperature-induced abnormalities in sheep oocytes during maturation. J. Reprod. Fertil. 75, 467-473.

Namula, Z., Sato, Y., Kodama, R., Morinaga, K., Luu, V. V., Taniguchi, M., Nakai, M., Tanihara, F., Kikuchi, K., Nagai, T. and Otoi, T. (2013): Motility and fertility of boar semen after liquid preservation at 5 degrees $C$ for more than 2 weeks. Anim. Sci. J. 84, 600-606.

Nobata, T., Kyougoku, H. and Miyano, T. (2013): Hematoxylin staining reveals a decrease in nucleolar diameter of pig oocytes before germinal vesicle breakdown. J. Reprod. Dev. 59, 500-505.

Otoi, T., Yamamoto, K., Horikita, N., Tachikawa, S. and Suzuki, T. (1999): Relationship between dead cells and DNA fragmentation in bovine embryos produced in vitro and stored at 4 degrees C. Mol. Reprod. Dev. 54, 342-347.

Pickering, S. J., Braude, P. R., Johnson, M. H., Cant, A. and Currie, J. (1990): Transient cooling to room temperature can cause irreversible disruption of the meiotic spindle in the human oocyte. Fertil. Steril. 54, 102-108.

Roth, Z. and Hansen, P. J. (2004): Involvement of apoptosis in disruption of developmental competence of bovine oocytes by heat shock during maturation. Biol. Reprod. 71, 1898-1906.

Tseng, J. K., Tang, P. C. and Ju, J. C. (2006): In vitro thermal stress induces apoptosis and reduces development of porcine parthenotes. Theriogenology 66, 1073-1082. 
Wolfenson, D., Roth, Z. and Meidan, R. (2000): Impaired reproduction in heat-stressed cattle: basic and applied aspects. Anim. Reprod. Sci. 60-61, 535-547.

Yuan, Y., Hao, Z. D., Liu, J., Wu, Y., Yang, L., Liu, G. S., Tian, J. H., Zhu, S. E. and Zeng, S. M. (2008): Heat shock at the germinal vesicle breakdown stage induces apoptosis in surrounding cumulus cells and reduces maturation rates of porcine oocytes in vitro. Theriogenology 70, $168-178$. 